\title{
Meta-analysis of the influence of Saccharomyces cerevisiae supplementation on ruminal parameters and milk production of ruminants
}

\author{
M. Desnoyers, ${ }^{\dagger} \dagger$ S. Giger-Reverdin, ${ }^{11}$ G. Bertin, $†$ C. Duvaux-Ponter, ${ }^{*}$ and D. Sauvant ${ }^{*}$ \\ *Unite Mixté de Recherches, Institut National de la Recherche Agnonomique-AgroParisTech Physiologie de la Nutrition et Alimentation, \\ 75231 Paris Cedex 05, France \\ †Alltech France, 92593 Levallois-Perret Cedex, France
}

\begin{abstract}
The effects of yeast supplementation on intake, production, and rumen fermentation characteristics have been widely studied, but results are inconsistent between different studies. A quantitative meta-analysis was applied to 110 papers, 157 experiments, and 376 treatments dealing with yeast supplementation in ruminants. The objective was first to highlight the major quantitative effects of live yeast supplementation on intake, rumen fermentation, and milk production, and second, to identify major differences in experimental conditions between studies that can affect the response to treatment. Some of these experimental conditions are referred to as interfering factors. Yeast supplementation increased rumen $\mathrm{pH}(+0.03$ on average $)$ and rumen volatile fatty acid concentration $(+2.17 \mathrm{mM}$ on average), tended to decrease rumen lactic acid concentration ( $-0.9 \mathrm{mM}$ on average), and had no influence on acetate-to-propionate ratio. Total-tract organic matter digestibility was also increased by yeast supplementation $(+0.8 \%$ on average $)$. Yeast supplementation increased dry matter intake (DMI; $+0.44 \mathrm{~g} / \mathrm{kg}$ of body weight; $\mathrm{BW})$, milk yield $(+1.2 \mathrm{~g} / \mathrm{kg}$ of $\mathrm{BW})$, and tended to increase milk fat content $(+0.05 \%)$, but had no influence on milk protein content. Dose effects of yeast supplementation, expressed as $\log _{10}[1+$ (cfu per $100 \mathrm{~kg}$ of BW)], globally confirmed the qualitative effects observed in the first analysis. The positive effect of yeast supplementation on rumen $\mathrm{pH}$ increased with the percentage of concentrate in the diet and with the DMI level. It was negatively correlated with the level of dietary neutral detergent fiber (NDF). The positive effect of yeast supplementation on rumen volatile fatty acid concentration increased with DMI and crude protein levels. The positive effect of yeast supplementation on organic matter digestibility increased with the percentage of concentrate and NDF in the diet. The negative effect of yeast supplementation on lactic acid
\end{abstract}

Received June 2, 2008.

Accepted November 28, 2008.

${ }^{1}$ Corresponding author: sylvie.giger-reverdin@agroparistech.fr concentration tended to decrease when the DMI level and the percentage of concentrate in the diet increased. The effects of interfering factors were globally similar when either dose effect or qualitative effect of yeast was taken into account. Although rumen fermentation efficiency per se was not measured, these results suggest an improvement in rumen fermentation by yeast supplementation. This effect could, however, be modulated by several different factors such as DMI, percentage of concentrate or NDF in the diet, or species.

Key words: meta-analysis, yeast, Saccharomyces cerevisiae, ruminant

\section{INTRODUCTION}

Most dietary compounds entering the rumen are degraded by numerous anaerobic microorganisms (mainly bacteria and protozoa) present in the rumen fluid. Thus, rumen ecosystem plays a key role in ruminants' responses to their diet. One of the consequences of feeding high-concentrate diets is the occurrence of subclinical ruminal acidosis (rumen $\mathrm{pH}<6.25$; Sauvant et al., 1999). Low $\mathrm{pH}$ in the rumen over long periods inhibits intake (Fulton et al., 1979; Owens et al., 1998) and plant cell wall digestion. This last aspect alters the energy value of the diet, particularly of its forage component. Moreover, the VFA profile in rumen fluid is altered with low acetate-to-propionate ratios (see reviews by Owens et al., 1998; Kleen et al., 2003; Sauvant et al., 2006) and sometimes a significant accumulation of lactic acid is observed (see review by Martin et al., 2006). Several authors have reviewed the influence of yeast supplementation on rumen digestion and ruminant performance. Some of these reviews mainly describe available papers on the whole yeast subject area but do not quantitatively analyze data available in these papers (Dawson, 2000; Jouany, 2001). Others present some quantitative analysis of yeast effects on milk production (Ali-Haimoud-Lekhal et al., 1999), rumen fermentation characteristics (Lescoat et al., 2000), or both (Robinson, 2002; Sauvant et al., 2004). Yeast seems to increase milk production (see reviews by Robinson, 2002; Abd El-Ghani, 2004; Stella et al., 2007) and to influence 
Table 1. Synthetic description of the database

\begin{tabular}{|c|c|c|c|c|}
\hline \multicolumn{4}{|l|}{ Categories } & \multirow{2}{*}{$\begin{array}{c}\text { nexp } \\
52 \\
16\end{array}$} \\
\hline \multirow[t]{10}{*}{ Species } & \multirow[t]{3}{*}{ Cattle } & \multirow[t]{2}{*}{ Dairy cattle } & With production data & \\
\hline & & & Without & $\begin{array}{l}16 \\
26\end{array}$ \\
\hline & & Others & & 9 \\
\hline & \multirow[t]{3}{*}{ Sheep } & Dairy & With production data & 1 \\
\hline & & Growing & & 5 \\
\hline & & Others & & 32 \\
\hline & \multirow[t]{2}{*}{ Goats } & Dairy & With production data & 6 \\
\hline & & Other & & 4 \\
\hline & \multirow{2}{*}{ Buffaloes } & Dairy & With production data & 2 \\
\hline & & Others & & 4 \\
\hline \multirow[t]{4}{*}{ Rumen $\mathrm{pH}$ measurement } & \multicolumn{3}{|c|}{ Esophageal tube } & 10 \\
\hline & \multicolumn{3}{|c|}{ Rumen cannula or rumenocentesis } & 49 \\
\hline & \multirow{2}{*}{\multicolumn{3}{|c|}{$\begin{array}{l}\text { Intra ruminal probe } \\
\text { Not stated }\end{array}$}} & 2 \\
\hline & & & & 7 \\
\hline
\end{tabular}

${ }^{1}$ nexp $=$ number of experiments.

several rumen parameters such as $\mathrm{pH}$, VFA concentration, and total-tract nutrient digestion (Erasmus et al., 1992; Robinson, 2002). Therefore, adding yeast to the rumen ecosystem seems to influence fermentation and might help the ecosystem to deal with high-concentrate diets. Results are, however, very inconsistent across experiments, and some quantitative reviews did not observe any significant influence of yeast supplementation on milk production in late-lactation dairy cows (AliHaimoud-Lekhal et al., 1999) or on rumen fermentation characteristics in cattle (Lescoat et al., 2000; Sauvant et al., 2004). The first objective of this paper was to provide an overview of the quantitative effects of yeast supplementation on dry matter intake, major rumen parameters (rumen $\mathrm{pH}, \mathrm{VFA}$ concentration, lactic acid concentration, and acetate-to-propionate ratio), and OM digestibility in both beef and dairy ruminants, and on production performance of lactating animals. The second objective of this paper was to determine if some interfering or confounding factors such as DMI or diet composition could influence the effect of yeast and thus determine in which situations yeasts are the most efficient.

\section{MATERIALS AND METHODS}

A database was constructed from experiments involving dietary yeast supplements. Only in vivo experiments using at least one strain of Saccharomyces cerevisiae were used to build the database. All ruminants species used for meat or milk production were included in the database (cattle, goats, sheep, and buffaloes). Selected papers contained at least data on rumen fermentation or digestibility measured in vivo, or milk production parameters for experiments involving dairy animals. Papers presenting more than one experiment or various dietary compositions were separated into experiments that were individually encoded. Each experiment contained 2 or more treatments (control vs. yeast), which were also individually encoded. A total of 110 papers comprising 157 experiments and 376 treatments were pooled in the database. The list of papers used is available in the appendix. A synthetic description of the database is presented in Table 1 . Yeast cultures were from at least 11 different live commercial preparations. More than half of the experiments (91 out of 157) used Yea-Sacc1026 (Alltech, Lexington, KY). For some of the studies, there was a lack of basic information on one or more of yeast concentration (73 experiments), BW of the animals (49 experiments), DMI (12 experiments), or chemical analysis of the diet (28 experiments). For these papers, BW was estimated according to the animal species, age, and sex; yeast concentration was estimated according to the commercial product used if data was available in another paper using the same product. Dry matter intake and milk yield (MY) were calculated per kilogram of BW to allow comparison between cattle and small ruminants. When rumen parameters were analyzed at several sampling times, the mean value was entered in the data set. No other precalculations were performed.

This whole data set was divided into a rumen data set $[81$ papers, number of experiments $($ nexp $)=116$; number of treatments $(\mathbf{n t})=277]$ and a production data set (50 papers, nexp $=61$; nt $=141)$. Interpretation of this database was based on a statistical metaanalysis (St-Pierre, 2001; Sauvant et al., 2008).

The basic statistical model applied to the data was

$$
\mathrm{Y}_{\mathrm{ijk}}=\mu+\mathrm{YEAST}_{\mathrm{i}}+\mathrm{EXP}_{\mathrm{j}}+\mathrm{E}_{\mathrm{ijk}},
$$

where $Y_{\mathrm{ijk}}=$ observations, $\mu=$ overall mean, $\mathrm{YEAST}_{\mathrm{i}}$ $=$ fixed effect of yeast, $\mathrm{EXP}_{\mathrm{j}}=$ fixed effect of experi- 
Table 2. Meta-analysis of the effect of yeast supplementation on rumen parameters and OM digestibility ${ }^{1}$

\begin{tabular}{|c|c|c|c|c|c|c|c|}
\hline Item $^{2}$ & nexp & nt & \multicolumn{2}{|c|}{ Treatment $^{2}$} & $P$-value & RMSE & $\mathrm{a}$ \\
\hline Rumen pH & 97 & 231 & 6.31 & 6.34 & $*$ & 0.11 & 17.5 \\
\hline Lactic acid $(\mathrm{mg} / \mathrm{L})$ & 16 & 38 & 1.21 & 1.13 & $\dagger$ & 0.15 & 12.5 \\
\hline OM digestibility (\%) & 45 & 103 & 70.2 & 71.0 & ** & 1.4 & 8.9 \\
\hline
\end{tabular}

ment $\mathrm{j}$, and $\mathrm{E}_{\mathrm{ijk}}=$ random residual error. All models were used without weighting the observations.

Yeast effect was first tested qualitatively (control vs. yeast) and then as a covariable according to level of yeast supplementation expressed as $\log _{10}[1+(\mathrm{cfu} / 100$ $\mathrm{kg}$ of $\mathrm{BW})]$ because the database contained both large and small ruminants. Normalized residuals (i.e., differences between model-predicted and measured value of the studied parameter, divided by the standard deviation of the residuals' values) were calculated to assess the ability of the model to fit the data. For each dependent variable, experiments presenting normalized residuals greater than 3.0 were discarded from the analysis but not from the analyses of other variables. For each statistical test, the considered parameters are least squares means (yeast vs. control) or the adjusted equation $\left[\log _{10}\right.$ (yeast concentration)], nexp, nt, the value of the root mean square error (RMSE), the $P$-value for yeast effect, and the percentage of "outlier treatments" that presented normalized residuals $>2.0$ (designated a). The fixed effect of experiment was always highly significant $(P<0.001)$ and is thus never provided. An effect was considered significant at $P<0.05$, considered a tendency toward significance at $P<0.1$, and $P$-values between 0.1 and 0.2 are discussed.

Differences in experimental conditions between studies can affect the response to treatment. Some of these experimental conditions can be represented by quantitative or qualitative interfering or confounding factors. These factors will be referred to as interfering factors throughout the manuscript. Analysis of the influence of some interfering factors was performed using data sets extracted from the main data sets, each data set containing only the experiments with available data on the interfering factor tested (Sauvant et al., 2008). For a given parameter, influence of interfering factors was assessed using, for each experiment, the slope of the response of the tested parameter as a function of yeast effect [yeast vs. control or $\log _{10}$ (yeast concentration)]. Effect of each potential interfering factor was tested on this slope by linear regression for quantitative pa- rameters or by one-factor ANOVA for qualitative ones. The intercept of the regression was fixed at zero if it was not significantly different from zero on the first analysis. For this statistical test, the provided information includes the mean, standard error, minimum and maximum values of the factors in the corresponding data set (because the influence of the factor could be dependent on the range used for analysis), the regression equation, nexp, the RMSE value of the regression, the $P$-value for the regression slope, and the percentage of "outlier treatments" that presented normalized residuals $>2.0$ (a). All statistical analyses were performed with Minitab (version 1.2, 1998, Minitab Inc., State College, PA).

\section{RESULTS}

\section{Rumen Fermentation and Digestibility}

Qualitative Analysis: Yeast Versus Control. Yeast supplementation increased rumen $\mathrm{pH}(P=0.023)$ and rumen VFA concentration $(P=0.005)$, and tended to decrease rumen lactic acid concentration $(P=0.099$; Table2). Yeast supplementation had no influence on acetate-to-propionate ratio $(P=0.9)$.

Table 3 presents the effects of interfering factors significantly influencing yeast effect. The positive effect of yeast supplementation on rumen $\mathrm{pH}$ tended to be increased by DMI (g per $\mathrm{kg}$ of BW; $P=0.07$ ), was increased by the proportion of concentrate in the diet $(P$ $=0.025)$, and was logically decreased by the proportion of NDF in the diet $(P=0.047)$. No influence of diet $\mathrm{CP}(P=0.5)$ was detected. The positive effect of yeast supplementation on rumen VFA concentration was increased by DMI $(P=0.007)$, and by the proportion of concentrate $(P<0.001)$, NDF $(P=0.041)$, and CP $(P$ $=0.031)$ in the diet. The negative effect of yeast supplementation on rumen lactic acid concentration tended to be attenuated by the proportion of concentrate in the $\operatorname{diet}(P=0.088)$ and DMI $(P=0.071)$. There was no influence of dietary NDF $(P=0.4)$ or $\mathrm{CP}(P=0.5)$ on 
Table 3. Effects of interfering factors on the qualitative effect of yeast supplementation on rumen parameters and OM digestibility

\begin{tabular}{|c|c|c|c|c|c|c|c|c|c|}
\hline Item & $\operatorname{nexp}^{1}$ & \multicolumn{4}{|c|}{ Interfering factor ${ }^{2}$} & Regression $^{3}$ & $\mathrm{RMSE}^{4}$ & $P$-value & $a^{5}$ \\
\hline \multicolumn{10}{|l|}{ Rumen pH } \\
\hline Concentrate (\%) & 77 & 50.5 & 26.08 & 0 & 100 & +0.001 & 0.15 & $*$ & 6.5 \\
\hline $\mathrm{NDF}(\% \mathrm{DM})$ & 48 & 40.9 & 15.31 & 21.5 & 80.1 & $0.16-0.004$ & 0.16 & $*$ & 8.3 \\
\hline \multicolumn{10}{|l|}{ VFA $(\mathrm{m} M)$} \\
\hline $\mathrm{CP}(\% \mathrm{DM})$ & 58 & 14.0 & 3.37 & 6.2 & 21.5 & +0.145 & 7.16 & $*$ & 6.9 \\
\hline \multicolumn{10}{|l|}{ Lactic acid $(\mathrm{m} M)$} \\
\hline DMI $(\mathrm{g} / \mathrm{kg}$ of $\mathrm{BW})$ & 15 & 26.3 & 7.85 & 14.4 & 44.3 & -0.004 & 0.23 & $\dagger$ & 6.7 \\
\hline Concentrate (\%) & 16 & 53.5 & 29.72 & 0 & 100 & -0.002 & 0.23 & $\dagger$ & 12.5 \\
\hline \multicolumn{10}{|l|}{ OM digestibility (\%) } \\
\hline DMI $(\mathrm{g} / \mathrm{kg}$ of $\mathrm{BW})$ & 39 & 28.1 & 9.56 & 10.8 & 46.3 & $2.20-0.052$ & 2.02 & 0.1 & 5.1 \\
\hline
\end{tabular}

${ }^{1}$ nexp $=$ number of experiments.

${ }^{2}$ Characteristics of the range available for the considered interfering factor: mean, standard deviation, minimum (Min), and maximum (Max).

${ }^{3}$ Regression equation (intercept is only presented when $\neq 0.00$ ).

${ }^{4} \mathrm{RMSE}=$ root mean square error.

${ }^{5}$ Percentage of treatments that presented normalized residuals larger than 2.0.

$\dagger P<0.10 ;{ }^{*} P<0.05 ;{ }^{* *} P<0.01 ; * * * P<0.001$.

the negative effect of yeast supplementation on rumen lactic acid concentration.

Organic matter digestibility was also increased by yeast supplementation $(P=0.007$; Table 2$)$, and the positive effect of yeast supplementation on OM digestibility was decreased by the proportion of concentrate in the $\operatorname{diet}(P=0.019)$ and increased by proportion of dietary NDF $(P=0.004$; Table 3$)$ No influence of dietary $\mathrm{CP}$ percentage $(P=0.21)$ or DMI $(P=0.14)$ was detected. There was no effect of species (cattle, sheep, or goat; $P>0.10)$ on any of the measured parameters.

Eight papers tested the effects of proportion of concentrate in the diet and yeast supplementation simultaneously, and 11 tested the effects of NDF content of the diet and yeast supplementation simultaneously. However, the meta-analysis performed using only these papers did not confirm the results of the analysis on the whole data set except for the effects of yeast supplementation on OM digestibility, which was increased by the proportion of NDF in the diet (regression slope $=$ $0.039, P=0.007, \mathrm{RMSE}=2.15$, nexp $=11)$. There was no significant influence of dietary concentrate proportion or NDF content on the effect of yeast supplementation on rumen $\mathrm{pH}$ (nexp $=17$ and 25 for concentrate and NDF, respectively), VFA concentration (nexp $=15$ and 23 for concentrate and NDF, respectively), or OM digestibility (nexp $=10$ for proportion of concentrate in the diet) in these specific papers.
Quantitative Analysis: Effect of Yeast Dose. Effects consistent with those obtained in the qualitative analysis were obtained with this second approach (Table 4$)$. Rumen $\mathrm{pH}(P=0.005)$ and VFA concentration $(P=0.022)$ increased linearly with yeast dose. Rumen lactic acid concentration was not influenced by yeast supplementation, but it should be noted that it approaches a level of significance $(P=0.101)$ and only 15 of the 81 experiments presented this data. Acetateto-propionate ratio was again not influenced by yeast supplementation $(P=0.8)$.

The effects of interfering factors on the quantitative effect of yeast supplementation on rumen fermentation characteristics are presented in Table 5 . The positive effect of yeast supplementation on rumen $\mathrm{pH}$ was again increased by the proportion of concentrate $(P=0.009)$, and decreased by the proportion of $\operatorname{NDF}(P=0.008)$ in the diet, but there was no effect of dietary $\mathrm{CP}(P$ $=0.3)$ or DMI $(P=0.3)$. The positive effect of yeast supplementation on rumen VFA concentration tended to be increased by the proportion of concentrate in the $\operatorname{diet}(P=0.084)$, but no influence of the proportion of dietary NDF $(P=0.6)$ or $\mathrm{CP}(P=0.3)$ in the diet or DMI $(P=0.19)$ was detected.

Organic matter digestibility also increased linearly with yeast dose $(P=0.004$; Table 4$)$. The effect of yeast supplementation on OM digestibility was decreased by the proportion of concentrate in the diet $(P=0.020)$ and increased by dietary NDF content $(P<0.001), \mathrm{CP}$ 
Table 4. Meta-analysis of the dose effect of yeast expressed as $\log 10(1+(\mathrm{cfu} / 100 \mathrm{~kg}$ of BW $))$ on rumen parameters and OM digestibility ${ }^{1}$

\begin{tabular}{|c|c|c|c|c|c|c|c|}
\hline Item & nexp & nt & Intercept & Slope & RMSE & $P$-value & $\mathrm{a}$ \\
\hline $\mathrm{pH}$ & 94 & 234 & 6.30 & +0.008 & 0.11 & ** & 17.6 \\
\hline VFA $(\mathrm{m} M)$ & 77 & 196 & 94.6 & +0.42 & 6.56 & $*$ & 14.3 \\
\hline Lactic acid $(\mathrm{m} M)$ & 15 & 38 & 1.21 & -0.015 & 0.15 & 0.1 & 13.3 \\
\hline
\end{tabular}

${ }^{1}$ nexp = number of experiments; $n t=$ number of treatments; RMSE $=$ root mean square error; $a=$ percentage of treatments that presented normalized residuals larger than 2.0.

${ }^{*} P<0.05 ; * * P<0.01$

content $(P=0.013)$, and DMI $(P=0.002$; Table 5$)$. There was no effect of species (cattle, sheep, or goat; $P$ $>0.10)$ on any of these parameters.

\section{Intake and Production Parameters}

Qualitative Analysis: Yeast Versus Control. Yeast supplementation increased DMI $(P=0.044)$ and milk yield $(P<0.001)$ and tended to increase milk fat content $(P=0.07)$, although it had no influence on milk protein content $(P=0.7$; Table 6$)$.

Table 7 presents the influence of the interfering factors, except species, on these effects. The positive effects of yeast supplementation on DMI was increased by the proportion of concentrate in the $\operatorname{diet}(P=0.043)$ but was not influenced by the proportion of $\operatorname{NDF}(P=$ $0.47)$ or $\mathrm{CP}(P=0.53)$ in the diet, or ruminant species $(P=0.16)$. Effect of yeast supplementation on MY was similar for cows and goats but was greater for buffaloes (mean slopes $=1.09,2.39$, and $6.19 \mathrm{~g}$ per $\mathrm{kg}$ of $\mathrm{BW}$, respectively; nexp $=49,5$, and 2 for cows, goats, and buffaloes, respectively; RMSE $=2.09 ; P=0.003)$. Only 2 experiments were conducted on buffaloes; thus, this result must be interpreted cautiously, and it cannot be concluded that the effects of yeast supplementation are always greater in buffaloes than in other dairy ruminants.

Influence of yeast supplementation on MY increased with DMI $(P<0.001)$ and with the proportion of concentrate $(P<0.001)$, NDF $(P=0.001)$, and $\mathrm{CP}(P=$ $0.001)$ in the diet. Yeast effect on milk fat content was not influenced by species $(P=0.5)$, DMI $(P=0.16)$, dietary $\mathrm{NDF}(P=0.9)$, or $\mathrm{CP}$ percentage $(P=0.6)$. It tended to be increased by the dietary concentrate percentage $(P=0.099)$.

Quantitative Analysis: Effect of Yeast Dose. Dry matter intake $(P=0.069)$ and $\mathrm{MY}(P<0.001)$ tended to increase linearly with yeast dose (Table 8 ). Milk fat and protein contents were not affected by yeast dose $(P>0.10)$.

Effect of yeast supplementation on DMI was neither influenced by the proportion of concentrate $(P=0.13)$, NDF $(P=0.51)$, or $\mathrm{CP}(P=0.53)$ in the diet, nor by ruminant species $(P=0.31)$. Only 1 experiment out of the 2 on buffaloes was included in the analysis of yeast dose effect on MY; thus, it was not included in the

Table 5. Effects of interfering factors on the dose effect of yeast supplementation on rumen parameters and OM digestibility

\begin{tabular}{|c|c|c|c|c|c|c|c|c|c|}
\hline \multirow[b]{2}{*}{ Item } & \multirow[b]{2}{*}{$\operatorname{nexp}^{1}$} & \multicolumn{4}{|c|}{ Interfering factor $^{2}$} & \multirow[b]{2}{*}{ Regression $^{3}$} & \multirow[b]{2}{*}{$\mathrm{RMSE}^{4}$} & \multirow[b]{2}{*}{$P$-value } & \multirow[b]{2}{*}{$a^{5}$} \\
\hline & & Mean & $\mathrm{SD}$ & Min & $\operatorname{Max}$ & & & & \\
\hline \multicolumn{10}{|l|}{ Rumen pH } \\
\hline Concentrate (\%) & 67 & 51.3 & 26.59 & 0 & 100 & +0.0001 & 0.03 & ** & 6.0 \\
\hline $\mathrm{NDF}(\%$ of DM) & 41 & 41.6 & 15.84 & 21.5 & 80.1 & $0.04-0.001$ & 0.03 & $* *$ & 7.3 \\
\hline \multicolumn{10}{|l|}{ VFA $(\mathrm{m} M)$} \\
\hline Concentrate (\%) & 63 & 48.2 & 26.82 & 0 & 100 & +0.005 & 1.2 & $\dagger$ & 6.3 \\
\hline Concentrate $(\%)$ & 36 & 43.8 & 23.54 & 0 & 100 & $0.50-0.006$ & 0.37 & * & 5.6 \\
\hline NDF ( $\%$ of DM) & 24 & 48.9 & 18.69 & 21.5 & 80.1 & +0.006 & 0.39 & $* * *$ & 8.3 \\
\hline $\mathrm{CP}(\%$ of $\mathrm{DM})$ & 31 & 12.7 & 3.10 & 6.2 & 18.0 & +0.014 & 0.39 & * & 9.7 \\
\hline
\end{tabular}

${ }^{1}$ nexp $=$ number of experiments.

${ }^{2}$ Characteristics of the range available for the considered interfering factor: mean, standard deviation, minimum (Min), and maximum (Max).

${ }^{3}$ Regression equation (intercept is only presented when $\neq 0.00$ ).

${ }^{4} \mathrm{RMSE}=$ root mean square error.

${ }^{5} \mathrm{a}=$ percentage of treatments that presented normalized residuals larger than 2.0.

$\dagger P<0.10 ; * P<0.05 ;{ }^{*} P<0.01 ; * * * P<0.001$. 
Table 6. Meta-analysis of the effect of yeast supplementation on intake and milk production ${ }^{1}$

\begin{tabular}{|c|c|c|c|c|c|c|c|}
\hline Item & nexp & $\mathrm{nt}$ & \multicolumn{2}{|c|}{ Treatment $^{2}$} & $P$-value & RMSE & $\mathrm{a}$ \\
\hline DMI (g/kg of BW) & 47 & 114 & 34.6 & 35.0 & $*$ & 1.1 & 12.8 \\
\hline Milk fat content (\%) & 57 & 131 & 3.80 & 3.85 & $\dagger$ & 0.14 & 12.3 \\
\hline Milk protein content (\%) & 52 & 121 & 3.20 & 3.19 & NS & 0.07 & 17.3 \\
\hline
\end{tabular}

${ }^{1}$ nexp = number of experiments; $n t=$ number of treatments; RMSE = root mean square error; a = percentage of treatments that presented normalized residuals larger than 2.0.

${ }^{2}$ Treatment values are given as least squares means.

$\mathrm{NS}=P \geq 0.10 ; \dagger P<0.10 ; * P<0.05 ; * * * P<0.001$.

analyses of species effect. Effect of yeast supplementation on milk yield tended to be greater for goats than for cows $(0.22$ and $0.74 \mathrm{~g}$ per $\mathrm{kg}$ of $\mathrm{BW}$, respectively; $\mathrm{n}=47$ and 2 , respectively; $\mathrm{RMSE}=0.37 ; P=0.60$; $\mathrm{a}=4.1 \%$ ), but only 2 experiments were available on goats. This result also must be interpreted cautiously, and it cannot be concluded that the effects of yeast supplementation is always greater in dairy goats than in cattle. Influence of yeast supplementation on MY increased with DMI $(P<0.001)$ and proportion of concentrate $(P=0.001), \mathrm{NDF}(P=0.001)$, and $\mathrm{CP}(P=$ 0.001 ) in the diet (Table 9$)$.

\section{DISCUSSION}

Although yeast increased milk production in numerous studies (Robinson, 2002; Abd El-Ghani, 2004; Stella et al., 2007) and influenced many rumen fermentation characteristics (Erasmus et al., 1992; Robinson, 2002), results are inconsistent across studies. This statement suggests that it could be possible to conclude either positive or negative effects of yeast supplementation for any given parameter depending upon the publications chosen. The authors cannot claim that the present analysis includes all research ever published on the supplementation of ruminant diets with yeasts, but have tried to be as exhaustive as possible in reviewing the literature. This current analysis of literature confirms the large variability in data between different papers; however, given the large number of papers used in this analysis, the process of interpretation within-experiment allowed extraction of the significant influences of yeast. Some difficulties were encountered during this analysis; these included incomplete data sets. Further, some experiments were only available as abstracts, posters, or in short communication form and data from some studies had not been published. This could induce a degree of bias in the meta-analysis because results that are not statistically significant are seldom presented in abstracts, posters, or short communications. This may be for a variety of reasons, including abstracts presented as preliminary studies that have not been validated by publication in a scientific paper, or nonpositive or nonsignificant results that have a lower probability of being

Table 7. Effects of interfering factors on the qualitative effect of yeast supplementation on intake and milk production

\begin{tabular}{|c|c|c|c|c|c|c|c|c|c|}
\hline Item & $\operatorname{nexp}^{1}$ & \multicolumn{4}{|c|}{ Interfering factor $^{2}$} & Slope $^{3}$ & $\mathrm{RMSE}^{4}$ & $P$-value & $a^{5}$ \\
\hline \multicolumn{10}{|l|}{ DMI (g/kg of BW) } \\
\hline \multicolumn{10}{|l|}{ Milk yield (g/kg of BW) } \\
\hline DMI (g/kg of BW) & 46 & 34.9 & 4.52 & 25.1 & 43.8 & +0.032 & 1.91 & $* * *$ & 4.3 \\
\hline Concentrate (\%) & 40 & 50.9 & 12.62 & 7.5 & 70.0 & +0.027 & 2.26 & $* * *$ & 5.0 \\
\hline \multicolumn{10}{|l|}{ Milk fat content (\%) } \\
\hline Concentrate (\%) & 39 & 51.3 & 12.51 & 7.50 & 70 & +0.001 & 0.17 & $\dagger$ & 5.1 \\
\hline
\end{tabular}

${ }^{1}$ nexp = number of experiments.

${ }^{2}$ Characteristics of the range available for the considered interfering factor: mean, standard deviation, minimum (Min), and maximum (Max).

${ }^{3}$ Regression slope (all the intercepts were $=0.00$ ).

${ }^{4} \mathrm{RMSE}=$ room mean square error.

${ }^{5} \mathrm{a}=$ percentage of treatments that presented normalized residuals larger than 2.0 .

$\dagger P<0.10 ;{ }^{*} P<0.05 ;{ }^{* *} P<0.01 ; * * * P<0.001$. 
Table 8. Meta-analysis of the dose effect of yeast expressed as $\log _{10}[1+(\mathrm{cfu} / 100 \mathrm{~kg}$ of BW $)]$ on intake and milk yield ${ }^{1}$

\begin{tabular}{lccccccc}
\hline Item & nexp & nt & Intercept & Slope & RMSE & $P$-value & a \\
\hline DMI (g/kg of BW) & 42 & 110 & 34.21 & +0.07 & 1.05 & $\dagger$ \\
Milk yield (g/kg of BW) & 53 & 134 & 47.8 & +0.21 & 1.59 & $* * *$ & 16.7 \\
\hline
\end{tabular}

${ }^{1}$ nexp $=$ number of experiments; nt $=$ number of treatments; RMSE $=$ root mean square error; $a=$ percentage of treatments that presented normalized residuals larger than 2.0 .

$\dagger P<0.10 ; * * *<0.001$.

published than positive or significant results. Twentyone of the papers used in this analysis ( 5 unpublished trials and 16 short papers) appeared to contain enough detail and were thus included in the data set. Seven short papers were used in the rumen fermentation database, and 15 in the production database, but no effect of paper form (short papers vs. full papers) was detected in any of the parameters tested.

The method of meta-analysis that was employed in this analysis is now considered the most suitable for this kind of study (St-Pierre, 2001; Sauvant et al., 2008). This method of statistical modeling has the major advantage of splitting variation among and within experiments. The present work is based on more papers than the one of Sauvant et al. (2004; 55 publications and 78 experiments) for in vivo studies, and thus certainly leads to more reliable conclusions. However, the power of this type of analysis can lead to the detection of very small significant differences that might be lower than the usual precision of the measurements for the studied parameter. For example, a significant difference of 0.03 $\mathrm{pH}$ unit was detected between yeast-supplemented and control animals. Although this result has to be confirmed by further studies, the fact that the difference in $\mathrm{pH}$ units is very small might explain why many papers did not show any influence of yeast supplementation on rumen $\mathrm{pH}$.

A difficulty of meta-analysis on in vivo data is that experimental methodologies and conditions vary greatly from one experiment to another, and thus a detailed analysis of some specific experimental factors that could explain, at least partly, the residual variations of the statistical analysis appeared to be necessary. The method of meta-analysis that we used did not allow analysis of the interactions between yeast and experimental factors, but the authors have tried to quantify this issue by a separate analysis of the influence of some potentially interfering factors on the yeast effect observed per experiment. This analysis shows that the composition of the diet influences the effects of yeast supplementation on rumen and production parameters, which was not clear using only the few papers simultaneously analyzing yeast effect and dietary parameters. This is certainly because of the low number of papers available. Another issue in meta-analysis is the way in which outlier treatments and experiments are treated. In the present paper, it was decided to discard the data that presented normalized residuals $>3.0$ and to calculate the proportion of data presenting normalized residuals $>2.0$.

Simultaneous analysis of qualitative and quantitative effects of yeast supplementation showed that results are mainly consistent between analyses, except for parameters showing a tendency toward qualitative effects of yeast supplementation but no dose effect. When a dose effect was detected, our statistical design did not allow determination of an eventual asymptote or maximum effect of yeast dose. Effects of interfering factors were

Table 9. Effects of interfering factors on dose effect of yeast supplementation on milk yield

\begin{tabular}{|c|c|c|c|c|c|c|c|c|c|}
\hline Item & $\exp ^{1}$ & \multicolumn{4}{|c|}{ Interfering factor ${ }^{2}$} & Slope $^{3}$ & $\mathrm{RMSE}^{4}$ & $P$-value & $a^{5}$ \\
\hline \multicolumn{10}{|c|}{ Milk yield (g/kg of BW) } \\
\hline Concentrate $(\%)$ & 36 & 50.4 & 12.77 & 7.5 & 70.0 & +0.005 & 0.40 & $* *$ & 5.6 \\
\hline $\mathrm{NDF}(\%$ of DM) & 17 & 34.5 & 5.39 & 26.2 & 16.5 & +0.007 & 0.26 & $* *$ & 0.0 \\
\hline $\mathrm{CP}(\%$ of $\mathrm{DM})$ & 22 & 16.1 & 2.26 & 11.8 & 19.0 & +0.016 & 0.29 & ** & 4.5 \\
\hline
\end{tabular}

${ }^{1}$ nexp $=$ number of experiments.

${ }^{2}$ Characteristics of the range available for the considered interfering factor: mean, standard deviation, minimum (Min) and maximum (Max).

${ }^{3}$ Regression slope (all the intercepts were $=0.00$ ).

${ }^{4} \mathrm{RMSE}=$ root mean square error.

${ }^{5} \mathrm{a}=$ percentage of treatments that presented normalized residuals larger than 2.0.

$* * P<0.01 ; * * * P<0.001$. 
also mainly consistent between the 2 analyses, even if fewer factors were significant for yeast dose effect. In particular, DMI was always significant when analyzed on a qualitative basis but only significant for OM digestibility when analyzed on a dose effect basis. This is certainly because yeasts are often given in the diet, and thus the level of yeast ingested is related to the level of DMI. In the qualitative analysis this effect of DMI might be confounded with yeast dose effect. Nonetheless, these results show that both methods are accurate in determining the effects of yeast supplementation and factors that interfere with this effect. Thus, papers with no indication of colony-forming units can be included in meta-analyses.

Yeast supplementation increased rumen $\mathrm{pH}$, VFA concentration, and $\mathrm{OM}$ digestibility and tended to decrease rumen lactate concentration. These results agree with the review of Robinson (2002; 14 experiments), which shows an average increase in $\mathrm{pH}(1.6 \%)$, an overall increase in total rumen VFA (5.4\%), and an overall decrease in lactate concentration (8.1\%). However, Lescoat et al. (2000), in their review using 40 papers, did not observe any influence of $S$. cerevisiae supplementation on rumen $\mathrm{pH}$ or $\mathrm{OM}$ digestibility but observed a greater increase in VFA concentration $(+4.8$ $\mathrm{mmol} / \mathrm{L}$ ) than that observed in the present analysis $(+2.1 \mathrm{mmol} / \mathrm{L})$. In addition, Sauvant et al. (2004), in a review using 78 experiments, did not observe any influence of yeast supplementation on rumen $\mathrm{pH}$ or VFA concentration, and only observed a tendency toward increase in $\mathrm{OM}$ digestibility $(+0.5 \%)$. This value is, however, similar to the one obtained in the present analysis (+0.8\%). Using the 157 experiments of the current meta-analysis certainly leads to more reliable statistical conclusions, even if all 157 experiments were not used for all the presented results. In the current meta-analysis, both rumen $\mathrm{pH}$ and VFA concentration are increased by yeast supplementation, and there was a tendency for lactic acid to be reduced. These results indicate that yeasts are able to limit the decrease in rumen $\mathrm{pH}$ that is usually linked to an increase in VFA. This confirms the observations of Giger-Reverdin et al. (2004), who observed an increase in the rumen buffering capacity of yeast-supplemented goats. Furthermore, yeasts were able to limit lactic acid production or accumulation in the rumen, although it was only a tendency. This decrease in lactic acid is, however, in agreement with the results of Chaucheyras-Durand and Fonty (2002). No influence of yeast was determined on the acetate-to-propionate ratio, which is coherent with the meta-analysis of Sauvant et al. (2004).

Dry matter intake and MY were increased by yeast supplementation, which again is in agreement with the review of Robinson (2002) and the analysis of Ali-
Haimoud-Lekhal et al. (1999), but the latter group observed a significant increase $(+1.3 \mathrm{~kg}$ per cow per day) only in early lactation. As physiological status was not always available in our data set, we could not test this hypothesis. The increase in milk yield observed by AliHaimoud-Lekhal et al. (1999) was far more important than the one observed in the present analysis $(+1.2$ $\mathrm{g}$ per $\mathrm{kg}$ of BW). This might be caused by the use of dairy animals in early and late lactation in the present paper. However, the present result suggests an overall increase in milk yield whatever the lactation state, and the lack of influence observed by Ali-Haimoud-Lekhal et al. (1999) might be caused by the smaller number of experiments used. This increase in MY is also in agreement with a study regrouping 22 experiments and showing an average increase in milk production of $7.3 \%$ for yeast-supplemented animals, even if this increase was often not significant (Jouany, 1999). However, Sauvant et al. (2004) only observed a tendency toward increased milk yield but no effect on DMI in their meta-analysis. Very little influence of yeast was observed on milk composition, only milk fat content tended to be increased by yeast supplementation, but this result was only observed for the qualitative effects of yeast supplementation. This is in agreement with previous analysis showing very little or inconsistent effects of yeast supplementation on milk composition (Ali-Haimoud-Lekhal et al., 1999; Robinson, 2002; Sauvant et al., 2004). The increase in milk production, usually observed when increasing dietary concentrate percentage, is often linked to a decrease in milk fat content. The current analysis shows that yeast supplementation increased milk yield without any significant effect on milk composition. Only 8 papers compared 2 types of yeast and only 3 of these compared the same yeast products; thus, our data set was unable to allow testing of the different types of yeast used.

Most of the interfering factors tested influenced animal response to yeast supplementation. This result suggests that many other factors not available in our database, for example, other dietary characteristics (e.g., starch content, net energy, physically effective fiber), physiological state (Ali-Haimoud-Lekhal et al., 1999), or management practices (Jouany, 1999; Beauchemin et al., 2003) might have to be tested. Yeast effect on MY is significantly enhanced with increased DMI (for both qualitative and dose effect analysis), and it is thus impossible with our analysis to determine if the increase in MY is a result of increased DMI, a physiological effect of yeast supplementation on milk production mechanisms, or a combination of both. Only the qualitative analysis of the effects of yeast supplementation on DMI was influenced by an interfering factor: the proportion of concentrate in the diet. This could be caused by the 
correlation between yeast dose and DMI when yeasts are incorporated in the diet. This might also indicate that factors other than those tested might interfere with the effects of yeast supplementation for this parameter. All these statements and questions confirm that DMI is a very important factor in ruminant production and digestion and that its effect cannot be easily dissociated from the effects of yeast supplementation.

All the rumen fermentation characteristics influenced by yeast supplementation are influenced by at least one of the dietary characteristics (proportion of concentrate, $\mathrm{NDF}$, or CP in the diet). The proportion of concentrate in the diet always interacted with the effects of yeast supplementation. Except for OM digestibility and lactic acid concentration, these results agree with previous observations showing that the influence of yeast supplementation on rumen parameters is greatest when using high-concentrate diets (Erasmus et al., 1992; Kung et al., 1997; Jouany, 1999) or with diets or feeding systems that reduce cellulolysis the most (Williams et al., 1991). This last statement is confirmed by rumen $\mathrm{pH}$ analysis, for which an increased proportion of NDF in the diet limited the effects of yeast. This is obviously in agreement with the fact that high-concentrate diets are commensurate with low levels of NDF in the diet. This is, however, not observed for other parameters (VFA concentration, OM digestibility, and MY), for which increasing dietary NDF enhances the effects of yeast supplementation. Yeast effect on rumen VFA seemed, thus, to be greater in high-concentrate or high-NDF diets than in intermediate ones. The increased effect in high-NDF diets is certainly caused by an increase in cellulolysis or the number of cellulolytic bacteria (Harrison et al., 1988). Crude protein was often the least significant interfering factor, showing that there might be fewer interactions between yeasts and nitrogen than between yeasts and concentrates or NDF. Nonetheless, all these results confirm that several factors can explain the variability observed between experiments and that many other experimental parameters might have to be tested in such databases to determine more precisely the conditions in which yeasts are the most effective. The type of production (milking vs. nonmilking animals for example) will certainly influence the effect of yeast supplementation on rumen parameters., but it was not possible to test this parameter because most of the experiments measuring rumen parameters are performed with nonmilking animals.

\section{CONCLUSIONS}

The meta-analysis of over 110 papers and 157 experiments showed that yeast supplementation increased DMI, MY, rumen $\mathrm{pH}$, rumen VFA concentration, and
OM digestibility, which was not always demonstrated in the previously published meta-analyses. It also indicated that dietary yeast supplementation tended to decrease rumen lactic acid concentration but had no effect on milk composition or rumen acetate-to-propionate ratio. For all parameters, with the exception of OM digestibility, yeast influence increased with the level of intake or the percentage of concentrate of the diet. Such analyses of interfering factors have never been published before and showed that numerous factors can interfere with the effect of yeast supplementation.

Despite the number of papers used and the use of meta-analysis as a powerful statistical tool, all of the issues discussed show that results have to be considered cautiously, as they are highly dependent upon the data set and the methodology used. Nonetheless, this analysis shows that both qualitative and dose effect approaches were relevant and showed similar results, indicating that papers that do not include the colonyforming units within their results can be included in meta-analyses.

\section{ACKNOWLEDGMENTS}

The authors thank Alltech France (Levallois Perret, France) for providing access to unpublished data of their internal trials and to abstracts and posters from their annual symposia.

\section{REFERENCES}

Abd El-Ghani, A. A. 2004. Influence of diet supplementation with yeast culture (Saccharomyces cerevisiae) on performance of Zaraibi goats. Small Rumin. Res. 52:223-229.

Ali-Haimoud-Lekhal, D., P. Lescoat, C. Bayourthe, and R. Moncoulon. 1999. Effets de Saccharomyces cerevisae et Aspergillus oryzae sur les performances zootechniques chez la vache laitière: Etude bibliographique. Page 157 in 6èmes Rencontres autour des Recherches sur les Ruminants, Paris, France.

Beauchemin, K. A., W. Z. Yang, D. P. Morgavi, G. R. Ghorbani, W. Kautz, and J. A. Z. Leedle. 2003. Effects of bacterial directfed microbials and yeast on site and extent of digestion, blood chemistry, and subclinical ruminal acidosis in feedlot cattle. J. Anim. Sci. 81:1628-1640.

Chaucheyras-Durand, F., and G. Fonty. 2002. Yeasts in ruminant nutrition. Experiences with a live yeast product. Kraftfutter. $85: 146-150$.

Dawson, K. A. 2000. Some milestones in our understanding of yeast culture supplementation in ruminants and their implications in animal production systems. Pages 473-486 in Alltech's 16th Annu. Symp. Biotechnol. Feed Ind., Lexington, KY.

Erasmus, L. J., P. M. Botha, and A. Kistner. 1992. Effect of yeast culture supplement on production, rumen fermentation, and duodenal nitrogen flow in dairy cows. J. Dairy Sci. 75:30563065.

Fulton, W. R., T. J. Klopfenstein, and R. A. Britton. 1979. Adaptation to high concentrate diets by beef cattle. 2 . Effect of ruminal $\mathrm{pH}$ alteration on rumen fermentation and voluntary intake of wheat diets. J. Anim. Sci. 49:785-789.

Giger-Reverdin, S., G. Bertin, J. Tessier, and D. Sauvant. 2004. Effet d'une levure (Saccharomyces Cerevisiae CBS 493.94) sur le métabolisme ruminal de la chèvre laitière. Page 265 in 11èmes 
Rencontres autour des Recherches sur les Ruminants, Paris, France.

Harrison, G. A., R. W. Hemken, K. A. Dawson, R. J. Harmon, and K. B. Barker. 1988. Influence of addition of yeast culture supplement to diets of lactating cows on ruminal fermentation and microbial populations. J. Dairy Sci. 71:2967-2975.

Jouany, J. P. 1999. Twenty years of research into yeast culture, now a standard in ruminant diets around the World. Pages 44-68 in Alltech's 15th Annu. Eur., Middle Eastern and African Lecture Tour. Responding to a Changing Agricultural Landscape, Lexington, $\mathrm{KY}$

Jouany, J.-P. 2001. A new look at yeast cultures as probiotics for ruminants. Feed Mix. 9:17-19.

Kleen, J. L., G. A. Hooijer, J. Rehage, and J. P. T. M. Noordhuizen. 2003. Subacute ruminal acidosis (SARA): A review. J. Vet. Med. A. 50:406-414.

Kung, L., E. M. Kreck, R. S. Tung, A. O. Hession, A. C. Sheperd, M. A. Cohen, H. E. Swain, and J. A. Z. Leedle. 1997. Effects of a live yeast culture and enzymes on in vitro ruminal fermentation and milk production of dairy cows. J. Dairy Sci. 80:2045-2051.

Lescoat, P., D. Ali-Haimoud-Lekhal, and C. Bayourthe. 2000. Effets de Saccharomyces cerevisiae et Aspergillus oryzae sur la digestion et le fonctionnement ruminal: Etude bibliographique. Page 199 in 7èmes Rencontres autour des Recherches sur les Ruminants, Paris, France.

Martin, C., L. Brossard, and M. Doreau. 2006. Mécanismes d'apparition de l'acidose ruminale latente et conséquences physiopathologiques et zootechniques. Prod. Anim. 19:93-108.

Owens, F. N., D. S. Secrist, W. J. Hill, and D. R. Gill. 1998. Acidosis in cattle: A review. J. Anim. Sci. 76:275-286.

Robinson, P. H. 2002. Yeast products for growing and lactating dairy cattle: impacts on rumen fermentation and performance. In XII Int. Meet. Milk Meat Prod. Hot Clim., Mexicali, Mexico.

Sauvant, D., S. Giger-Reverdin, and F. Meschy. 2006. Le contrôle de l'acidose ruminale latente. Prod. Anim. 19:69-78.

Sauvant, D., S. Giger-Reverdin, and P. Schmidely. 2004. Rumen acidosis: Modeling ruminant response to yeast culture. Pages 221-229 in Alltech's 20th Annu. Symp. Biotechnol. Feed Ind. Reimagining the Feed Industry. T. P. Lyons and K. A. Jacques, ed. Nottingham University Press.

Sauvant, D., F. Meschy, and D. Mertens. 1999. Les composantes de l'acidose ruminale et les effets acidogènes des rations. Prod. Anim. 12:49-60.

Sauvant, D., P. Schmidely, J. Daudin, and N. R. St-Pierre. 2008. Meta-analyses of Experimental Data in Animal Nutrition. Anim. $2: 1203-1214$

St-Pierre, N. R. 2001. Integrating quantitative findings from multiple studies using mixed model methodology. J. Dairy Sci. 84:741755 .

Stella, A. V., R. Paratte, L. Valnegri, G. Cigalino, G. Soncini, E. Chevaux, V. Dell'Orto, and G. Savoini. 2007. Effect of administration of live Saccharomyces cerevisiae on milk production, milk composition, blood metabolites, and faecal flora in early lactating dairy goats. Small Rumin. Res. 67:7-13.

Williams, P. E., C. A. Tait, G. M. Innes, and C. J. Newbold. 1991 Effects of the inclusion of yeast culture (Saccharomyces cerevisiae plus growth medium) in the diet of dairy cows on milk yield and forage degradation and fermentation patterns in the rumen of steers. J. Anim. Sci. 69:3016-3026.

\section{APPENDIX}

\section{References Used for Meta-Analysis}

Abd El-Ghani, A. A. 2004. Influence of diet supplementation with yeast culture (Saccharomyces cerevisiae) on performance of Zaraibi goats. Small Rumin. Res. 52:223-229.

Adamovic, M. 1998. The influence of Yea-Sacc ${ }^{1026}$ on milk production, milk composition and physiology of food digestion in dairy cows during mid-lactation. Poster in Alltech's 14th Annu. Symp. Biotechnol. Feed Ind., Lexington, KY.
Adams, A. L., B. Harris Jr., H. H. Van Horn, and C. J. Wilcox. 1995. Effects of varying forage types on milk production responses to whole cottonseed, tallow, and yeast. J. Dairy Sci. 78:573-581.

Adams, D. C., M. L. Galyean, H. E. Kiesling, J. D. Wallace, and M. D. Finkner. 1981. Influence of viable yeast culture, sodium bicarbonate and monensin on liquid dilution rate, rumen fermentation and feedlot performance of growing steers and digestibility in lambs. J. Anim. Sci. 53:780-789.

Ali-Haimoud-Lekhal, A. D., and E. Chevaux. 2003. Effet d'un apport de Levucell SC dans l'alimentation de la vache laitière sur la production et sur la composition du lait. Page 391 in 10ème Rencontres autour des Recherches sur les Ruminants, Paris, France.

Alshaikh, M. A., M. Y. Alsiadi, S. M. Zahran, H. H. Mogawer, and T. A. Aalshowime. 2002. Effect of feeding yeast culture from different sources on the performance of lactating Holstein cows in Saudi Arabia. Asian-australas. J. Anim. Sci. 15:352-356.

Andrighetto, I., L. Bailoni, G. Cozzi, and P. Berzaghi. 1993. Effects of yeast culture addition on digestion in sheep fed a high concentrate diet. Small Rumin. Res. 12:27-34.

Angeles, S. C., G. D. Mendoza, M. A. Cobos, M. M. Crosby, and F. A. Castrejon. 1998. Comparison of two commercial yeast cultures (Saccharomyces cerevisiae) on ruminal fermentation and digestion in sheep fed on corn-stover diet. Small Rumin. Res. 31:45-50.

Arakaki, L. C., R. C. Stahringer, J. E. Garrett, and B. A. Dehority 2000. The effects of feeding monensin and yeast culture, alone or in combination, on the concentration and generic composition of rumen protozoa in steers fed on low-quality pasture supplemented with increasing levels of concentrate. Anim. Feed Sci. Technol. 84:121-127.

Arambel, M. J., and B. A. Kent. 1990. Effect of yeast culture on nutrient digestibility and milk yield response in early- to midlactation dairy cows. J. Dairy Sci. 73:1560-1563.

Arcos-Garcia, J. L., F. A. Castrejon, G. D. Mendoza, and E. P. Perez-Gavilan. 2000. Effect of two commercial yeast cultures with Saccharomyces cerevisiae on ruminal fermentation and digestion in sheep fed sugar cane tops. Livest. Prod. Sci. 63:153-157.

Aydin, C., N. Galip, K. Yaman, F. Cengiz, I. I. Turkmen, and H. Biricik. 2003. Effect of Saccharomyces cerevisiae live yeast culture on ruminal metabolites and protozoa in male Kivircik yearlings fed a high forage and concentrate diet. Turk. J. Vet. Anim. Sci. 27:1433-1440.

Bach, A., C. Iglesias, and M. Devant. 2007. Daily rumen pH pattern of loose-housed dairy cattle as affected by feeding pattern and live yeast supplementation. Anim. Feed Sci. Technol. 136:146-153.

Baumann, T. A., A. E. Radunz, G. P. Lardy, V. L. Anderson, J. S. Caton, and M. L. Bauer. 2004. Effects of tempering and a yeast-enzyme mixture on intake, ruminal fermentation, in situ disappearance, performance, and carcass traits in steers fed barleybased diets. Prof. Anim. Sci. 20:178-184.

Beauchemin, K. A., W. Z. Yang, D. P. Morgavi, G. R. Ghorbani, W. Kautz, and J. A. Z. Leedle. 2003. Effects of bacterial directfed microbials and yeast on site and extent of digestion, blood chemistry, and subclinical ruminal acidosis in feedlot cattle. J. Anim. Sci. 81:1628-1640.

Bertin, G., and S. Andrieu. 2005. Effect of yeast culture (Yea-Sac ${ }^{1026}$ ) supplementation on performance of high producing dairy cows. Poster in Alltech's 21st Annu. Symp. Biotechnol. Feed Ind., Lexington, KY.

Besong, S., J. A. Jackson, C. L. Hicks, and R. W. Hemken. 1996. Effects of a supplemental liquid yeast product on feed intake, ruminal profiles, and yield, composition, and organoleptic characteristics of milk from lactating Holstein cows. J. Dairy Sci. 79:1654-1658.

Biricik, H., and H. M. Yavuz. 2001. Effects of Saccharomyces cerevisiae yeast culture on milk production, milk composition and some rumen and blood parameters of dairy cows. J. Facul. Vet. Med. 19:9-17.

Carro, M. D., P. Lebzien, and K. Rohr. 1992. Effects of yeast culture on rumen fermentation, digestibility and duodenal flow in dairy cows fed a silage based diet. Livest. Prod. Sci. 32:219-229. 
Chademana, I., and N. W. Offer. 1990. The effect of dietary inclusion of yeast culture on digestion in the sheep. Anim. Prod. 50:483489

Chiquette, J. 1995. Saccharomyces cerevisiae and Aspergillus oryzae, used alone or in combination, as a feed supplement for beef and dairy cattle. Can. J. Anim. Sci. 75:405-415.

Corona, L., G. D. Mendoza, F. A. Castrejon, M. M. Crosby, and M. A. Cobos. 1999. Evaluation of two yeast cultures (Saccharomyces cerevisiae) on ruminal fermentation and digestion in sheep fed a corn stover diet. Small Rumin. Res. 31:209-214.

Dann, H. M., J. K. Drackley, G. C. McCoy, M. F. Hutjens, and J. E. Garrett. 2000. Effects of yeast culture (Saccharomyces cerevisiae) on prepartum intake and postpartum intake and milk production of Jersey cows. J. Dairy Sci. 83:123-127.

Dawson, K. A., K. E. Newman, and J. A. Boling. 1990. Effects of microbial supplements containing yeast and lactobacilli on roughage-fed ruminal microbial activities. J. Anim. Sci. 68:33923398.

De Queiroz, R. C., A. F. Bergamaschine, J. F. P. Bastos, P. C. d. Santos, and G. C. Lemos. 2004. Use of enzymes and yeast in the cattle diet: Nutrient digestibility and performance in feedlots. Rev. Bras. Zootec. 33:1548-1556.

Dehghan-Banadaky, M., A. Nik-Khah, and A. Zali. 2003. Effects of feeding yeast (Saccharomyces cerevisiae) on productive performance and blood components of lactating Holstein dairy cows. Page 106 in Proc. Br. Soc. Anim. Sci., York, UK.

Dobos, R. C., A. J. Dickens, and T. J. Norris. 1989. Yea-Sacc for dairy cattle in low concentrate input systems: Effects on milk yield and composition in an Australian experiment. Alltech (internal communication). Alltech, Lexington, KY.

Dolezal, P., J. Dolezal, and J. Trinacty. 2005. The effect of Saccharomyces cerevisiae on ruminal fermentation in dairy cows. Czech J. Anim. Sci. 50:503.

Doreau, M., and J. P. Jouany. 1998. Effect of a Saccharomyces cerevisiae culture on nutrient digestion in lactating dairy cows. J. Dairy Sci. 81:3214-3221.

El-Hassan, S. M., C. J. Newbold, I. E. Edwards, J. H. Topps, and R. J. Wallace. 1996. Effect of yeast culture on rumen fermentation, microbial protein flow from the rumen and live-weight gain in bulls given high cereal diets. Anim. Sci. 62:43-48.

El-Nor, S. A. H. A., and A. M. Kholif. 1998. Effect of supplementation of live yeast culture in the diet on the productive performance of lactating buffaloes. Milchwissenschaft 53:663-666.

El-Waziry, A. M., H. E. M. Kamel, and M. H. M. Yacout. 2000. Effect of bakers' yeast (Saccharomyces cerevisiae) supplementation to berseem (Trifolium alexandrinum) hay diet on protein digestion and rumen fermentation of sheep. Egypt. J. Nutr. Feed. 3:71-82.

Enjalbert, F., J. E. Garrett, R. Moncoulon, C. Bayourthe, and P. Chicoteau. 1999. Effects of yeast culture (Saccharomyces cerevisiae) on ruminal digestion in non-lactating dairy cows. Anim. Feed Sci. Technol. 76:195-206

Erasmus, L. J., P. M. Botha, and A. Kistner. 1992. Effect of yeast culture supplement on production, rumen fermentation, and duodenal nitrogen flow in dairy cows. J. Dairy Sci. 75:3056-3065.

Erasmus, L. J., P. H. Robinson, A. Ahmadi, R. Hinders, and J. E. Garrett. 2005. Influence of prepartum and postpartum supplementation of a yeast culture and monensin, or both, on ruminal fermentation and performance of multiparous dairy cows. Anim. Feed Sci. Technol. 122:219-239.

Erdman, R. A., and B. K. Sharma. 1989. Effect of yeast culture and sodium bicarbonate on milk yield and composition in dairy cows. J. Dairy Sci. 72:1929-1932.

Fiems, L. O., B. G. Cottyn, and C. V. Boucque. 1995. Effect of yeast supplementation on health, performance and rumen fermentation in beef bulls. Arch. Anim. Nutr. 47:295-300.

Flachowsky, G., K. Tiroke, and M. Matthey. 1993. Influence of yeast (Saccharomyces cerevisiae as Yea-Sacc or Levaferm) on in sacco dry matter degradability and ruminal parameters of variously fed small ruminants. Arch. Anim. Nutr. 42:159-169.

Galip, N. 2006a. Effects of dietary Saccharomyces cerevisiae live yeast culture supplementation on ruminal digestion and protozoa count in rams fed with diets with low or high ratio forage/concentrate. Rev. Med. Vet. 157:607-611.

Galip, N. 2006b. Effect of supplemental yeast culture and sodium bicarbonate on ruminal fermentation and blood variables in rams. J. Anim. Physiol. Anim. Nutr. (Berl.) 90:446-452.

Galip, N. 2006c. Effect of supplemental yeast culture on ruminal protozoa and blood parameters in rams. Rev. Med. Vet. 157:519 524.

Garcia, C. C. G., M. G. D. Mendoza, M. S. Gonzalez, P. M. Cobos, C. M. E. Ortega, and L. R. Ramirez. 2000. Effect of a yeast culture (Saccharomyces cerevisiae) and monensin on ruminal fermentation and digestion in sheep. Anim. Feed Sci. Technol. 83:165-170.

Garza-Cazares, F., P. Lebzien, and G. Flachowsky. 2001. Effect of Saccharomyces cerevisiae on in sacco dry matter degradability and parameters of rumen fermentation in sheep. Pages 501-504 in Vitamine und Zusatzstoffe in der Ernährung von Mensch und Tier. 8 Symp., Jena/Thuringen, Germany.

Giger-Reverdin, S., N. Bezault, D. Sauvant, and G. Bertin. 1996 Effects of a probiotic yeast in lactating ruminants: Interaction with dietary nitrogen level. Anim. Feed Sci. Technol. 63:149-162.

Giger-Reverdin, S., D. Sauvant, J. Tessier, G. Bertin, and P. MorandFehr. 2004. Effect of live yeast culture supplementation on rumen fermentation in lactating dairy goats. S. Afr. J. Anim. Sci. 34(Suppl. 1):59-61.

Günther, K. D. 1988. Effect of Yea-Sacc on milk yield, composition and feed intake of dairy cows. Alltech (internal communication). Alltech, Lexington, KY.

Haddad, S. G., and S. N. Goussous. 2005. Effect of yeast culture supplementation on nutrient intake, digestibility and growth performance of Awassi lambs. Anim. Feed Sci. Technol. 118:343348.

Hadjipanayiotou, M., I. Antoniou, and A. Photiou. 1997. Effects of the inclusion of yeast culture on the performance of dairy ewes and goats and the degradation of feedstuffs. Livest. Prod. Sci. 48:129-134.

Harris, B., Jr., D. E. Dorminey, W. A. Smith, H. H. Van Horn, and C. J. Wilcox. 1992. The effect of Yea-Sacc supplementation on milk yield and composition under large herd management conditions. J. Dairy Sci. 75(Suppl. 1):313. (Abstr.)

Harrison, G. A., R. W. Hemken, K. A. Dawson, R. J. Harmon, and K. B. Barker. 1988. Influence of addition of yeast culture supplement to diets of lactating cows on ruminal fermentation and microbial populations. J. Dairy Sci. 71:2967-2975.

Henics, Z., and S. Gombos. 1991. Effects of yeast culture on milk production, feed digestibility and ruminal fermentation of dairy cattle. Poster in Alltech's 7th Annu. Symp. Biotechnol. Feed Ind., Lexington, KY

Huber, J. T., J. Sullivan, and B. Taylor. 1988. Effect of feeding YeaSacc on milk production and related responses in a commercial dairy herd in Arizona. Pages 35-38 in Alltech's 5th Annu. Symp. Biotechnol. Feed Ind., Lexington, KY

Huhtanen, P. 1991. Effects of yeast culture supplement on digestion of nutrients and rumen fermentation in cattle fed on grass silage barley diet. J. Agric. Sci. Finland. 63:443-453.

José, M. V. and R. R. 2000. Effect of Yea-Sacc supplementation on milk production and post-partum reproductive behavior in dairy cattle. Alltech (internal communication). Alltech, Lexington, KY.

Jouany, J. P., F. Mathieu, J. Senaud, J. Bohatier, G. Bertin, and M. Mercier. 1998. The effect of Saccharomyces cerevisiae and Aspergillus oryzae on the digestion of the cell wall fraction of a mixed diet in defaunated and refaunated sheep rumen. Reprod. Nutr. Dev. 38:401-416.

Kamalamma, U. K., and P. Krishnappa. 1996. Effect of feeding yeast culture (Yea-Sacc1026) on rumen fermentation in vitro and production performance in crossbred dairy cows. Anim. Feed Sci. Technol. 57:247-256.

Kampf, D., A. Raasch, P. Möckel, and G. Flachowsky. 1997. Einfluss lebender Hefezellen auf Kennzahlen der Pansenfermentation und den in sacco Trockensubstanzabbau von Weizenstroh une Luzerneheu bei nicht laktierenden Kühen. Pages 482-485 in 
Vitamine und Zusatzstoffe in der Ernâhrung von Mensch und Tier, Jena, Thüringen, Germany.

Karr, K. J. K. R. McLeod, K. A. Dawson, R. E. Tucker, and G. E. Mitchell. 1991. Influence of yeast culture and/or monensin on nitrogen flow and rumen fermentation in sheep. Poster in Alltech's 7th Annu. Symp. Biotechnol. Feed Ind., Lexington, KY.

Kawas, J. R., R. Garcia-Castillo, H. Fimbres-Durazo, F. GarzaCazares, J. F. G. Hernandez-Vidal, E. Olivares-Saenz, and C. D. Lu. 2007. Effects of sodium bicarbonate and yeast on nutrient intake, digestibility, and ruminal fermentation of light-weight lambs fed finishing diets. Small Rumin. Res. 67:149-156.

Khadem, A. A., M. Pahlavan, A. Afzalzadeh, and M. Rezaeian. 2007. Effects of live yeast Saccharomyces cerevisiae on fermentation parameters and microbial populations of rumen, total tract digestibility of diet nutrients and on the in situ degradability of alfalfa hay in Iranian Chall sheep. Pak. J. Biol. Sci. 10:590-597.

Kim, D. Y., M. R. Figueroa, D. P. Dawson, C. E. Batallas, M. J. Arambel, and J. L. Walters. 1992a. Efficacity of supplemental viable yeast culture with or without Aspergillus oryzae on nutrient digestibility and milk production in early to midlactation dairy cows. Abstract; Alltech (internal communication). Alltech, Lexington, $\mathrm{KY}$.

Kim, D. Y., B. A. Kent, M. R. Figueroa, D. P. Dawson, C. E. Batallas, M. J. Arambel, and J. L. Walters. 1992b. Effect of added yeast culture with or without Aspergillus oryzae on rumen fermentation and nutrient digestibility when fed to nonlactating Holstein cows. Abstract; Alltech (internal communication). Alltech, Lexington, KY.

Kobayashi, T., and H. Itabashi. 1995. Effects of yeast culture on milk protein yield, ruminal fermentation and blood measurements in early and mid-lactation cows. Poster in Alltech's 11th Annu. Symp. Biotechnol. Feed Ind., Lexington, KY.

Koul, V., U. Kumar, V. K. Sareen, and S. Singh. 1998. Mode of action of yeast culture (YEA-SACC 1026) for stimulation of rumen fermentation in buffalo calves. J. Sci. Food Agric. 77:407-413.

Kumar, U., V. K. Soneen, and S. Singh. 1992. A note on the effect of supplementation of yeast culture (Saccharomyces cerevisiae plus growth medium) in the diet of buffaloes on milk yield and composition. Anim. Prod. 55:440-442.

Kumar, U., V. K. Sareen, and S. Singh. 1994. Effect of Saccharomyces cerevisiae yeast culture supplement on ruminal metabolism in buffalo calves given a high concentrate diet. Anim. Prod. 59:209215.

Kung, L., Jr., E. M. Kreck, R. S. Tung, A. O. Hession, A. C. Sheperd, M. A. Cohen, H. E. Swain, and J. A. Z. Leedle. 1997. Effects of a live yeast culture and enzymes on in vitro ruminal fermentation and milk production of dairy cows. J. Dairy Sci. 80:2045-2051.

Lodge, S., T. J. Klopfenstein, R. Stock, and D. Herold. 1996. Use of direct fed microbials to alleviate subacute acidosis. Pages 66-67 in 1996 Nebraska Beef Cattle Report, University of NebraskaLincoln, Lincoln.

Malcolm, K. J., and H. E. Kiesling. 1990. Effects of whole cottonseed and live yeast culture on ruminal fermentation and fluid passage rate in steers. J. Anim. Sci. 68:1965-1970.

Mathieu, F., J. P. Jouany, J. Senaud, J. Bohatier, G. Bertin, and M. Mercier. 1996. The effect of Saccharomyces cerevisiae and Aspergillus oryzae on fermentations in the rumen of faunated and defaunated sheep; protozoal and probiotic interactions. Reprod. Nutr. Dev. 36:271-287.

Michalet-Doreau, B., and D. Morand. 1996. Effect of yeast culture, Saccharomyces cerevisiae, on ruminal fermentation during adaptation to high concentrate feeding. Ann. Zootech. 45(suppl.):337.

Mir, Z., and P. S. Mir. 1994. Effect of the addition of live yeast (Saccharomyces cerevisiae) on growth and carcass quality of steers fed high-forage or high-grain diets and on feed digestibility and in situ degradability. J. Anim. Sci. 72:537-545.

Miranda, R. L. A., M. G. D. Mendoza, J. R. Barcena-Gama, M. S. S. Gonzalez, R. Ferrara, C. M. E. Ortega, and P. M. A. Cobos. 1996. Effect of Saccharomyces cerevisiae or Aspergillus oryzae cultures and NDF level on parameters of ruminal fermentation. Anim. Feed Sci. Technol. 63:289-296.

Moloney, A. P., and M. J. Drennan. 1994. The influence of the basal diet on the effects of yeast culture on ruminal fermentation and digestibility in steers. Anim. Feed Sci. Technol. 50:55-73.

Mpofu, I. D. T., and L. R. Ndlovu. 1994. The potential of yeast and natural fungi for enhancing fibre digestibility of forages and roughage. Anim. Feed Sci. Technol. 48:39-47.

Mutsvangwa, T., I. E. Edwards, J. H. Topps, and G. F. M. Paterson. 1992. The effect of dietary inclusion of yeast culture (Yea-Sacc) on patterns of rumen fermentation, food intake and growth of intensively fed bulls. Anim. Prod. 55:35-40.

Newbold, C. J., R. J. Wallace, X. B. Chen, and F. M. McIntosh. 1995 Different strains of Saccharomyces cerevisiae differ in their effects on ruminal bacterial numbers in vitro and in sheep. J. Anim. Sci. 73:1811-1818.

Newbold, C. J., R. J. Wallace, and F. M. McIntosh. 1996. Mode of action of the yeast Saccharomyces cerevisiae as a feed additive for ruminants. Br. J. Nutr. 76:249-261.

Nocek, J. E., W. P. Kautz, J. A. Z. Leedle, and J. G. Allman. 2002. Ruminal supplementation of direct-fed microbials on diurnal $\mathrm{pH}$ variation and in situ digestion in dairy cattle. J. Dairy Sci. 85:429 433

Oetzel, G. R., K. M. Emery, W. P. Kautz, and J. E. Nocek. 2007. Direct-fed microbial supplementation and health and performance of pre- and postpartum dairy cattle: A field trial. J. Dairy Sci. 90:2058-2068.

Olson, K. C., J. S. Caton, D. R. Kirby, and P. L. Norton. 1994a. Influence of yeast culture supplementation and advancing season on steers grazing mixed-grass prairie in the northern Great Plains. 2. Ruminal fermentation, site of digestion, and microbial efficiency. J. Anim. Sci. 72:2158-2170.

Olson, K. C., J. S. Caton, D. R. Kirby, and P. L. Norton. 1994b. Influence of yeast culture supplementation and advancing season on steers grazing mixed-grass prairie in the northern Great Plains. 1. Dietary composition, intake, and in situ nutrient disappearance. J. Anim. Sci. 72:2149-2157.

Pitamic, S., U. Pestevsek, and J. Zust. 1994. The influence of yeast culture addition in ration of dairy cows in postpartal period on energy balance, rumen fermentation and milk production. Poster in Alltech's 10th Annu. Symp. Biotechnol. Feed Ind., Lexington, KY

Piva, G., S. Belladonna, G. Fusconi, and F. Sicbaldi. 1993. Effects of yeast on dairy cow performance, ruminal fermentation, blood components, and milk manufacturing properties. J. Dairy Sci. $76: 2717-2722$.

Plata, P. F., G. D. Mendoza, J. R. Barcena-Gama, and S. Gonzalez. 1994. Effect of a yeast culture (Saccharomyces cerevisiae) on neutral detergent fiber digestion in steers fed oat straw based diets. Anim. Feed Sci. Technol. 49:203-210.

Preissinger, W., A. Maierhofer, and A. Obermaier. 2004. Effect of yeast culture (Saccharomyces cereviesiae) on nutrient digestibility, feed intake and milk yield response in Simmental dairy cows. Poster in Alltech's 20th Annu. Symp. Biotechnol. Feed Ind., Lexington, KY.

Putnam, D. E., C. G. Schwab, M. T. Socha, N. L. Whitehouse, N. A. Kierstead, and B. D. Garthwaite. 1997. Effect of yeast culture in the diets of early lactation dairy cows on ruminal fermentation and passage of nitrogen fractions and amino acids to the small intestine. J. Dairy Sci. 80:374-384.

Quigley, J. D., III, L. B. Wallis, H. H. Dowlen, and R. N. Heitmann. 1992. Sodium bicarbonate and yeast culture effects on ruminal fermentation, growth, and intake in dairy calves. J. Dairy Sci. $75: 3531-3538$.

Quinonez, J. A., L. J. Bush, T. Nalsen, and G. D. Adams. 1988. Effect of yeast culture on intake and production of dairy cows fed high wheat rations. Pages 227-232 in Animal Science Research Reports of the Oklahoma Agricultural Experiment Station, MP125, Stillwater, OK

Roa, V. M. L., J. R. Barcena-Gama, M. S. Gonzalez, M. G. Mendoza C. M. E. Ortega, and B. C. Garcia. 1997. Effect of fiber source and 
a yeast culture (Saccharomyces cerevisiae1026) on digestion and the environment in the rumen of cattle. Anim. Feed Sci. Technol. 64:327-336.

Robinson, P. H., and J. E. Garrett. 1999. Effect of yeast culture (Saccharomyces cerevisiae) on adaptation of cows to postpartum diets and on lactational performance. J. Anim. Sci. 77:988-999.

Rouzbehan, Y., H. Galbraith, J. A. Rooke, and J. G. Perrott. 1994 A note on the effects of dietary inclusion of a yeast culture on growth and ruminal metabolism of lambs given diets containing unground pelleted molassed dried sugar-beet pulp and barley in various proportions. Anim. Prod. 59:147-150.

Schingoethe, D. J., K. N. Linke, K. F. Kalscheur, A. R. Hippen, D. R. Rennich, and I. Yoon. 2004. Feed efficiency of mid-lactation dairy cows fed yeast culture during summer. J. Dairy Sci. 87:41784181.

Semptey, F. 1991. Effect of Yea-Sacc ${ }^{1026}$ on degradability of feedstuffs for ruminants. Poster in Alltech's 7th Annu. Symp. Biotechnol. Feed Ind., Lexington, KY.

Sinclair, L. A., K. A. Ranson, S. J. Ames, and D. Wilde. 2006. The effect of including a yeast culture on the intake performance of high yielding dairy cows fed a diet high in starch. Page 125 in Proc. Br. Soc. Anim. Sci., York, UK.

Skorko-Sajko, H., J. Sajko, and W. Zalewski. 1993. The effect of Yea-Sacc1026 in the ration for dairy cows on production and composition of milk. J. Anim. Feed Sci. 2:159-167.

Smith, W. A., B. Harris Jr., H. H. Van Horn, and C. J. Wilcox. 1993 Effects of forage type on production of dairy cows supplemented with whole cottonseed, tallow, and yeast. J. Dairy Sci. 76:205215

Sobhani, R., S. R. Valizadeh, and A. A. Nasserian. 2004. Effect of yeast culture on feed intake and productive performance of lactating dairy cows fed on barley silage based diets. Page 172 in Proc. Br. Soc. Anim. Sci., York, UK.

Soder, K. J., and L. A. Holden. 1999. Dry matter intake and milk yield and composition of cows fed yeast prepartum and postpartum. J. Dairy Sci. 82:605-610.

Stella, A. V., R. Paratte, L. Valnegri, G. Cigalino, G. Soncini, E. Chevaux, V. Dell'Orto, and G. Savoini. 2007. Effect of administration of live
Saccharomyces cerevisiae on milk production, milk composition, blood metabolites, and faecal flora in early lactating dairy goats. Small Rumin. Res. 67:7-13.

Swartz, D. L., L. D. Muller, G. W. Rogers, and G. A. Varga. 1994. Effect of yeast cultures on performance of lactating dairy cows: A field study. J. Dairy Sci. 77:3073-3080.

Tarvydas, V., R. Mankevicius, and S. Bliznikas. 1993. Effects of viable yeast culture on milk production intake, nutrient digestibility, nitrogen availability and rumen fermentation of lactating cows. Poster in Alltech's 9th Annu. Symp. Biotechnol. Feed Ind.

Thomas, J. 1988. Effect of Yea-Sacc on milk volume, milk quality cow condition and silage intake. Alltech (internal communication). Alltech, Lexington, KY.

Wang, Z., M. L. Eastridge, and X. Qiu. 2001. Effects of forage neutral detergent fiber and yeast culture on performance of cows during early lactation. J. Dairy Sci. 84:204-212.

Weiss, W. 1991. Effect of Yea-Sacc1026 on milk yield and composition at a German dairy. Poster in Alltech's 7th Annu. Symp. Biotechnol. Feed Ind., Lexington, KY.

Wiedmeier, R. D., M. J. Arambel, and J. L. Walters. 1987. Effect of yeast culture and Aspergillus oryzae fermentation extract on ruminal characteristics and nutrient digestibility. J. Dairy Sci. 70:2063-2068.

Williams, P. E., C. A. Tait, G. M. Innes, and C. J. Newbold. 1991 Effects of the inclusion of yeast culture (Saccharomyces cerevisiae plus growth medium) in the diet of dairy cows on milk yield and forage degradation and fermentation patterns in the rumen of steers. J. Anim. Sci. 69:3016-3026.

Wohlt, J. E., A. D. Finkelstein, and C. H. Chung. 1991. Yeast culture to improve intake, nutrient digestibility, and performance by dairy cattle during early lactation. J. Dairy Sci. 74:1395-1400.

Yoon, I. K., and M. D. Stern. 1996. Effects of Saccharomyces cerevisiae and Aspergillus oryzae cultures on ruminal fermentation in dairy cows. J. Dairy Sci. 79:411-417.

Zinn, R. A., E. G. Alvarez, S. Rodriguez, and J. Salinas. 1999. Influence of yeast culture on health, performance and digestive function of feedlot steers. J. Anim. Sci. 77(Suppl. 1):335-338. 